Aneta Kacprzak', Izabela Siemion-Szcześniak', Monika Szturmowicz', Iwona Bestry ${ }^{2}$, Renata Langfort ${ }^{3}$, Jan Kuśs

'I Department of Lung Diseases, National Tuberculosis and Lung Diseases Research Institute, Warsaw, Poland

Head: Prof. J. Kuś, MD, PhD

${ }^{2}$ Department of Radiology, National Tuberculosis and Lung Diseases Research Institute, Warsaw, Poland

Head: I. Bestry

${ }^{3}$ Department od Pathology, National Tuberculosis and Lung Diseases Research Institute, Warsaw, Poland

Head: R. Langfort, MD

\title{
Pulmonary pathology in patients with ulcerative colitis treated with mesalazine - a challenging and complex diagnostic problem. Case series and literature review
}

\author{
Choroba płuc u pacjentów z wrzodziejącym zapaleniem jelita grubego leczonych \\ mesalazyną — trudny problem diagnostyczny. Seria przypadków i przegląd literatury \\ The authors declare no financial disclosure
}

\begin{abstract}
Pulmonary involvement in the course of inflammatory bowel disease has been a subject of interest to clinicians for long time, but despite this, its epidemiology and potential pathomechanisms remain obscured. Equally unclear is the role of medications used for bowel disease treatment in lung disease development. We present three patients with ulcerative colitis, all treated with mesalazine, in whom unexplained lung disease developed. Due to different clinical and radiological presentation, different conditions were initially placed on the top of the differential list in each of them. The outcome was favourable in all patients despite differences in management. We compared our patients with similar cases from literature. We show the level of difficulty and complexity in the issue of lung disease in patients with inflammatory bowel disease.
\end{abstract}

Key words: inflammatory bowel disease, ulcerative colitis, mesalazine, lung disease

Pneumonol. Alergol. Pol. 2014; 82: 368-376

\section{Streszczenie}

Zagadnienie zajęcia płuc w przebiegu nieswoistych zapaleń jelit pozostaje przedmiotem zainteresowania klinicystów od dawna. Pomimo to epidemiologia tego zjawiska ani potencjalne patomechanizmy nie są znane. Niewyjaśniona jest także rola leków stosowanych w zapaleniach jelit w rozwoju patologii płucnej. W pracy przedstawiono troje pacjentów z wrzodziejącym zapaleniem jelita grubego leczonych mesalazyną, u których rozwinęła się choroba płuc. Z powodu różnej prezentacji klinicznej i radiologicznej, wstępna diagnostyka u każdego z nich ukierunkowana była na inne jednostki chorobowe. Zastosowane postępowanie u każdego z nich również było inne. Dokonaliśmy porównania naszych pacjentów do podobnych przypadków opisanych w literaturze. Opisani przez nas pacjenci dobrze obrazują, jak trudne i złożone jest zagadnienie chorób płuc rozwijających się u pacjentów z nieswoistymi zapaleniami jelit.

Słowa kluczowe: nieswoiste zapalenia jelit, wrzodziejące zapalenie jelita grubego, mesalazyna, choroba płuc

Pneumonol. Alergol. Pol. 2014; 82: 368-376

Address for correspondence: Aneta Kacprzak, I Department of Lung Diseases, National Tuberculosis and Lung Diseases Research Institute, ul. Plocka 26, 01-138 Warszawa

DOI: 10.5603/PiAP.2014.0047

Praca wpłynęła do Redakcji: 7.01.2014 r.

Copyright (c) 2014 PTChP

ISSN 0867-7077 


\section{Introduction}

Ulcerative colitis (UC), Crohn's disease and a subgroup of colitis difficult to classify constitute a group of inflammatory conditions called inflammatory bowel disease (IBD) [1, 2]. Nowadays, IBD is considered to be a systemic rather than exclusively gastrointestinal disorder. This is a consequence of the vast burden of information on so-called extraintestinal manifestations of IBD [3-6]. There is a common belief shared by gastroenterologists and chest physicians that the lungs are, although rarely, one of the targeted organs in IBD. It is, however, based on clinicians' observations only. Unfortunately, no proper epidemiological investigations have ever been conducted to prove it, so the subject remains controversial. Storch et al. [7] have summarised more than 400 cases of pulmonary manifestations of IBD, published over a period of 50 years. Here, we enrich the literature on that subject by adding three more cases that support the hypothesis of a connection between IBD and pulmonary pathology, and show the complexity of the issue.

\section{Case reports}

\section{Case 1}

A 26-year-old, never-smoking, working as a shop assistant, Caucasian woman with UC was referred to our centre due to respiratory symptoms and abnormal findings in chest imaging studies. UC was diagnosed one year earlier. It had been treated with a three-month course of systemic glucocorticosteroids (GCs) at the beginning, and with oral mesalazine in a daily dose of $2.0 \mathrm{~g}$ for the last 8 months.

At the time of referral to our unit the bowel disease had been exacerbated for three months and dry cough, left-sided pleural chest pain and low-grade fever had been present for a month. Computed tomography (CT) of the chest performed 10 days before the admission showed multiple nodules and irregular masses scattered bilaterally in the lungs, thickening of the pleura and traces of fluid in the left pleural cavity; lymph nodes and remaining structures of the chest were normal. On admission she was apyrexial, and physical examination revealed pale skin, body mass index (BMI) 22.8, heart rate (HR) 100 beats per minute (bpm), blood pressure (BP) 130/65 mm Hg, respiratory rate (RR) $16 / \mathrm{min}$, oxygen saturation $\left(\mathrm{SaO}_{2}\right) 99 \%$, no enlarged peripheral lymph nodes, no peripheral oedema and no abnormalities on chest auscultation or abdomen palpation.
Blood tests showed leucocytosis $14.15 \times 10^{9} / \mathrm{L}$ with neutrophilia $12.05 \times 10^{9} / \mathrm{L}$; eosinophils (eo) were normal. Erythrocyte sedimentation rate (ESR) was $115 \mathrm{~mm} / \mathrm{h}$, C-reactive protein (CRP) $63.4 \mathrm{mg} / \mathrm{L}$ (normal limit < 10), antinuclear antibody (ANA) titre 1:640 and anti-neutrophil cytoplasmic antibody (ANCA) negative. Renal and liver parameters as well as arterialised blood gases were normal. Chest X-ray (Fig. 1a) showed round -shaped shadows, the largest having a diameter of $33 \mathrm{~mm}$ localised in the lower field of the left lung, and features of fluid presence in both pleural cavities. The radiologic features, especially on CT scans, were suggestive of an inflammatory character of the changes, including bacterial, fungal and tuberculosis infection, but could also be seen in haematological malignancies. There were no abnormalities within the airways in a bronchofiberoscopy; bronchial secretions were obtained for a broad spectrum of tests. Following this initial work-up the patient was given a 10-day course of an empirical antibiotic therapy (levofloxacin $500 \mathrm{mg}$ bd orally). It resulted in normalisation of WBC $\left(9.3 \times 10^{9} / \mathrm{L}\right)$, but other inflammatory indices remained significantly increased (CRP 54.6 $\mathrm{mg} / \mathrm{L}$ and ESR $120 \mathrm{~mm} / \mathrm{h}$ ). Microbiological and mycological cultures as well as tuberculosis tests (microscopic study, genetic probe) of bronchial secretions were negative and the cytology was irrelevant. There was no improvement on chest X-ray, and follow-up CT scanning (Fig. 1b) of the chest showed increase of the size of nodules when compared to a study performed one month earlier. At that stage a histological verification was required. The patient underwent left-sided video-assisted thoracoscopy with resection of the mass from the left lower lobe. A microscopic examination revealed confluent active inflammation of the type of organising pneumonia with eosinophilic infiltrates, which in the opinion of the histopathologist could have been either associated with inflammatory bowel disease itself or drug (mesalazine) - induced. The cessation of mesalazine and treatment with systemic GCs were intended. The patient, however, declined the offered management and decided to continue to take mesalazine.

At a 3-months follow-up visit her condition was significantly improved, symptoms relating to the respiratory system disappeared. She still suffered from intestine-related problems. Blood tests were within normal limits. Chest X-ray revealed the regression of changes seen before, with only residual linear scars in the lower zone of the left lung. Pulmonary function tests showed 

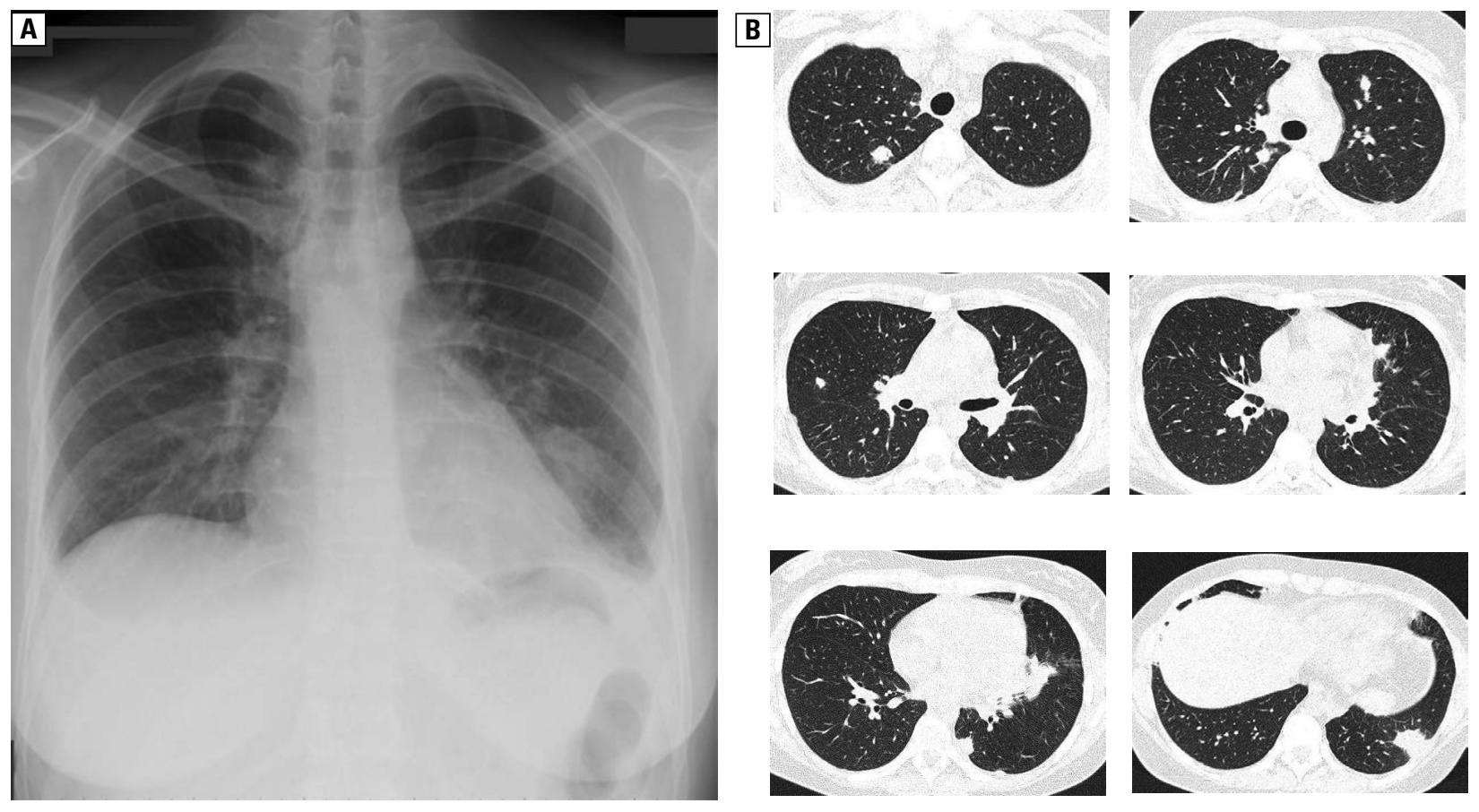

Figure 1. Case 1; A - chest x-ray; B - HRCT scans show multiple nodular opacities, more extensive in the left lower lobe

normal values of volumes and DLCO remained at the level of $70 \%$ of predicted.

\section{Case 2}

A 31-year-old, never-smoking, working in an office Caucasian man with UC diagnosed five years earlier, treated for this reason with oral and rectal preparations of mesalazine, having features of mild exacerbation of the intestinal disease for the last few days, presented with dry cough, right-sided chest pains of pleural type and fever. The symptoms had been present for 3 weeks and had not responded to an antibiotic and inhaled bronchodilators prescribed by his GP. Chest X-ray performed two weeks after the onset of the disease showed subpleural opacities in the middle/lower field of the right lung. Chest X-ray repeated one week later (Fig. 2a) revealed progression of these abnormalities.

The patient's condition at the time of admission to the hospital was fair; he was apyrexial but suffering from oppressive dry cough and pleural pain. Physical examination revealed BMI 23, HR 98 bpm, BP 140/90 mm Hg, RR 18/min, $\mathrm{SaO}_{2}$ $97 \%$, peripheral lymph nodes were not enlarged and peripheral oedema was not present. Normal vesicular breathing sound was heard on chest auscultation; however, it was slightly reduced at the base of the right lung. Blood tests were as follows: WBC $16.47 \times 10^{9} / \mathrm{L}$, neu $9.9 \times 10^{9} / \mathrm{L}$, eo $2.24 \times 10^{9} / \mathrm{L}$, ESR $80 \mathrm{~mm} / \mathrm{h}$, CRP $27.5 \mathrm{mg} / \mathrm{L}$,
ANA titre 1:160 and ANCA negative. Renal and liver parameters as well as arterialised blood gases were normal. Pulmonary angiography CT (Fig. 2b) was performed because a pulmonary embolism was one of the differential diagnoses. No contrast filling defects within the pulmonary artery bed were found. However, the lung window of the CT study showed multiple subpleural parenchymal consolidations in the right lung. No mediastinal lymphadenopathy or pleural fluid was seen. Localisation and morphology of lung abnormalities were highly suggestive of organising pneumonia. Bronchofiberoscopy was carried out showing normal airways. Bronchoalveolar lavage (BAL) was performed, and immunological cell differential was as follows: macrophages 80.5\% (normal > 90\%), lymphocytes - 13.5\% (normal < 10\%), neutrophils - 5.5\% (normal $<3 \%$ ), eosinophils $-0.5 \%$ (normal $<0.5 \%$ ). Lymphocyte CD4+/CD8+ ratio was 2.74 (normal range 1.5-2.5). Other results of BAL fluid examination, i.e. microbiological cultures and cytology, were not relevant. Due to the patient's cough and a characteristic picture of CT findings, transbronchial lung biopsy was considered not only unsafe but also unnecessary. Based on clinical and radiological presentation, high eosinophil count in peripheral blood, coexistence of UC and mesalazine intake, a diagnosis of organising pneumonia associated with either inflammatory bowel disease or, more probably, with mesala- 


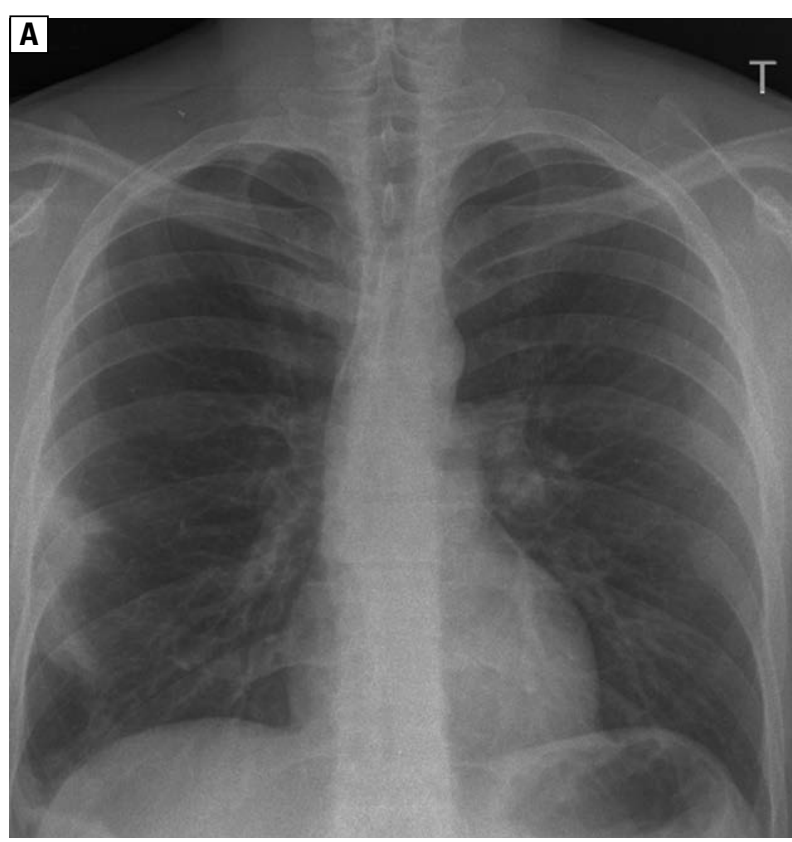

zine toxicity was established. Mesalazine was stopped and treatment with oral prednisone 50 $\mathrm{mg}$ a day $(0.6 \mathrm{mg} / \mathrm{kg}$ of body weight $)$ and inhaled ciclesonide 320 micrograms bd (to relieve severe cough) was commenced. It resulted in an rapid improvement of the symptoms, normalisation of blood eosinophils count within three days, and partial resolution of changes on chest x-ray seen after one week of the treatment. The dose of prednisone was slowly reduced to $30 \mathrm{mg}$ a day and the patient was seen again three months later. He was in good condition, free of any respiratory symptoms. Inflammatory indices were not elevated: ERS $5 \mathrm{~mm} / \mathrm{h}$, CRP $<5 \mathrm{mg} / \mathrm{L}$. WBC was 11.29 $\times 10^{9} / \mathrm{L}$ and eosinophils count was $0.15 \times 10^{9} / \mathrm{L}$. High resolution CT (HRCT) of the lungs showed complete regression of parenchymal lesions. Pulmonary function tests (not performed previously due to oppressive cough) showed: $\mathrm{FEV}_{1} 103 \%$ of predicted value (pred), VC $104 \%$ of pred, $\mathrm{FEV}_{1} /$ /VC 0.84 , RV $148 \%$ of pred, TLC $113 \%$ of pred, RV/TLC 0.31 , DLCO $84 \%$ of pred. The patient was recommended to continue treatment with prednisone in decreasing doses until final withdrawal within another three months.

\section{Case 3}

A 65-year-old, retired, never-smoking Caucasian woman with UC was admitted to our Department due to respiratory symptoms and abnormal findings in imaging studies of the chest. UC had been diagnosed 2.5 years earlier. It had been treated with prednisone for a short initial period and, subsequently, with oral mesalazine for many
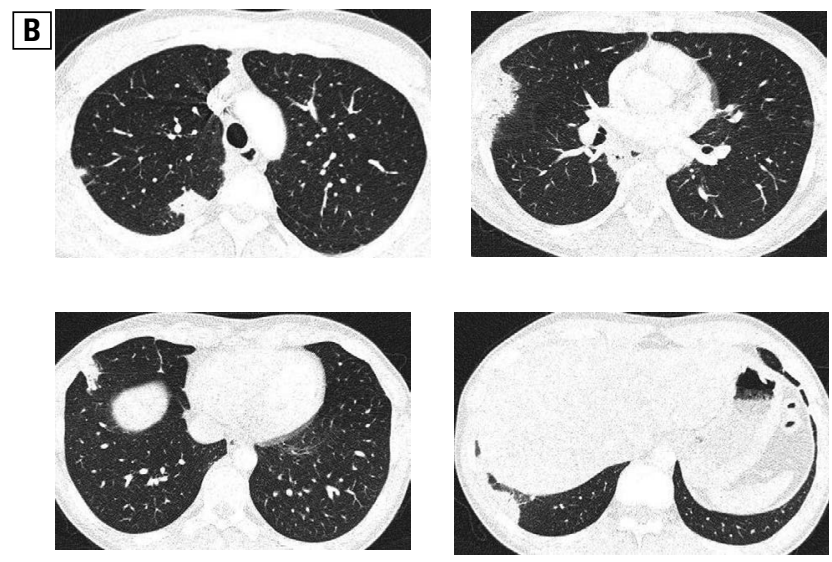

Figure 2. Case 2; A - chest x-ray; B — chest CT scans show multiple subpleural consolidations in the right lung

months. The patient noticed exertional breathlessness one year prior to admission, but for the last six months it had been more troublesome. Sweating and body weight loss, $8 \mathrm{~kg}$ in total, also occurred. The patient's daughter had pulmonary tuberculosis a couple of years earlier. For these reasons chest CT examination was carried out and it showed inhomogeneous attenuation of the lung parenchyma with irregularly scattered subtle interstitial patchy opacities, especially in the upper lobes and superior segment of the right lower lobe. At the time of exaggeration of respiratory symptoms, UC became active, too. Shortly after the aforementioned chest CT was performed, the patient was admitted to a gastroenterology department, where oral prednisone in a starting dose of $60 \mathrm{mg}$ a day and 6-mercaptopurine were added to the treatment. It resulted in improvement of both bowel and respiratory symptoms.

The patient presented to our unit three weeks after discharge from the gastroenterology department. She continued on prednisone $(55 \mathrm{mg} /$ /day), 6-mercaptopurine and oral mesalazine $3 \mathrm{~g} /$ /day. Her exertional breathlessness was improved and she was free of intestinal symptoms. She had normal body temperature, BMI 27.6, HR 84 bpm, BP 130/80 mmHg, RR 16/min, $\mathrm{SaO}_{2} 96 \%$, no enlarged peripheral lymph nodes, no peripheral oedema and no abnormalities on chest auscultation or abdomen palpation. Blood cell count, renal and liver parameters and arterialised blood gases were normal. ESR was $11 \mathrm{~mm} / \mathrm{h}$, CRP 6.3 mg/L, ANA titre 1:100 and cANCA was positive 

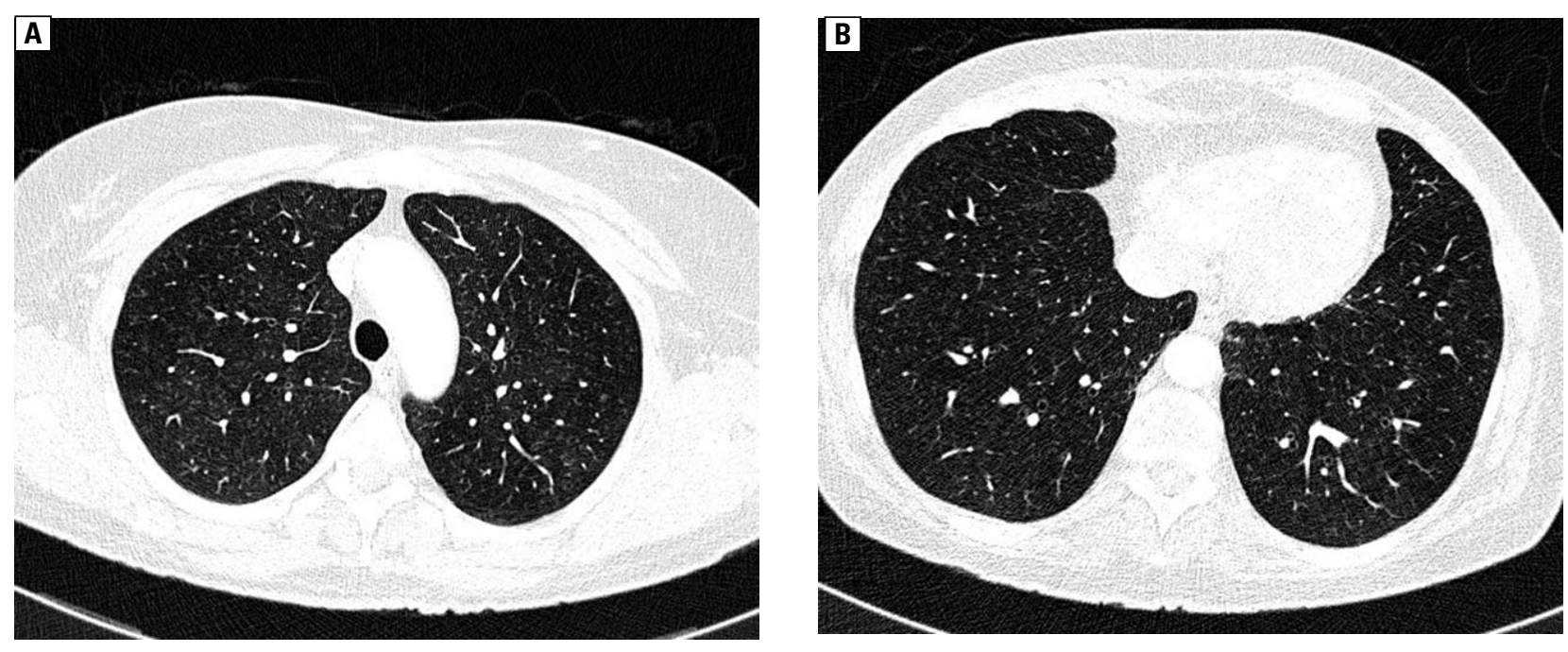

Figure 3. Case 3: HRCT scans show diffuse, ill-defined nodules within both lungs

in titre 1:40. There were no significant alterations in chest X-ray. CT scan showed partial regression of previously seen diffuse interstitial abnormalities, subtle centrilobular nodules were still present in the upper lobes (Fig. 3). Pulmonary function tests revealed irreversible mild airway obstruction and hyperinflation of the lungs $\left(\mathrm{FEV}_{1}\right.$ $78 \%$ of predicted, VC $115 \%$ of predicted, $\mathrm{FEV}_{1} /$ /VC 0.65 , RV $170 \%$ of predicted, TLC $129 \%$ of predicted and RV/TLC 0.56 ) with normal DLCO (75\% of predicted). BAL fluid differential count was as follows: macrophages $58.1 \%$, lymphocytes $39.4 \%$, neutrophils $2.5 \%$ and eosinophils $0.0 \%$. Lymphocyte CD4+/CD8+ ratio was 3.4. Transbronchial lung biopsy was planned but could not be performed due to the patient's poor cooperation. Microscopic examination of BAL fluid for acid-fast bacilli was negative, but the genetic probe was positive. The culture was ultimately inconclusive as it was contaminated. Blood T-SPOT TB test yielded a negative result. This fact and the significant clinical and radiological improvement on prednisone therapy were clear evidence against infectious aetiology, including tuberculosis. A watchful waiting attitude was adopted and the patient was recommended to continue with treatment according to the plan of the gastroenterologists in charge. She has been seen in our Department twice since then. During one-year follow-up she remained free of respiratory symptoms, her chest X-ray stayed stable and DLCO fluctuated slightly around 70\% of predicted. The respiratory symptoms did not recur even when prednisone was stopped and she continued treatment with mesalazine.

\section{Discussion}

The differential diagnosis of pulmonary pathology in patients with inflammatory bowel disease embraces: infections, including opportunistic ones in patients taking GCs and/or other immunosuppressive agents, pneumonitis associated with IBD, pulmonary complications induced by used medications, and thromboembolic disease. Additional considerations are related to the presence of ANA and/or ANCA, frequently seen in association with IBD [8-11]. Differentiation is usually challenging, as it was in the presented cases. In addition, there is no specific marker or a single test that could differentiate between a coincidental pulmonary disorder and one potentially related to IBD or a drug-induced one. Establishing the ultimate diagnosis involves a broad set of additional investigations and a dose of clinician's arbitrary opinion.

All the presented patients suffered from ulcerative colitis, the diagnosis of which preceded occurrence of respiratory system disease by one year in case 1 , five years in case 2 and two and a half years in case 3 . All had been treated with oral mesalazine when respiratory disease occurred; the duration of the treatment ranged from eight months (case 1) to five years (case 2). Patient 2 was using mesalazine rectal suppositories in addition to its oral preparation. In Patient 1 , respiratory symptoms developed one month after the beginning of UC flare, in Patient 2 concomitantly with mild UC exacerbation, while Patient 3 suffered from exertional breathlessness for several months before a flare of UC. Presentation 
of Patient 1 and 2 shared a lot of similarities, with an acute beginning and domination of cough, pleural chest pain and fever, whereas in Patient 3 prolonged exertional dyspnoea, sweats and body weight loss were the main symptoms. All of them had abnormal lungs in imaging studies. The review of 27 published cases [12-33] of IBD patients (19 UC and 8 Crohn's disease patients) treated with oral mesalazine, in whom lung disease developed, showed that presentation of our patients was typical. The most common symptoms reported in the literature included: exertional breathlessness (22/27 patients), fever (18/27 patients), cough (18/27 patients), pleuritic chest pain (8/27 patients), body weight loss (4/27 patients) and sweats (2/27 patients). In 12 (44\%) patients a triad of breathlessness, fever and cough was present. The median duration of exposure to mesalazine was 8 months (range 2 days -8 years). Respiratory disease appeared in association with IBD flare as well as in the period of its quiescence. Our patients were in good/fair condition and had normal blood gases, but the literature shows that a vast proportion of similar patients presented with hypoxaemia of varying degree, some of them requiring admission to an intensive care unit $[25,33]$. Data on imaging studies (chest X-ray, CT scanning) were given for 25 of the reviewed patients. Bilateral changes were seen in 21 patients, unilateral changes (interestingly right-sided in all cases) in 3 patients and in 1 patient imaging studies were normal. The broad spectrum of radiological findings, from the subtle thickening of the interstitium through centrilobular nodules, ground glass opacities, nonspecific opacities (migratory in one case) to multiple pulmonary nodules, was seen. Pleural fluid was present in three cases. Similarly, each of our patients had a different radiologic pattern of the lung. In Case 1, bilateral nodules and pleural effusion were present. In Case 2, multiple subpleural consolidations were seen in the right lung and in Case 3, centrilobular nodules were present. Data on WBC and blood eosinophilia were available for 16 reviewed IBD patients. In 10 patients the number of eosinophils in the blood was normal. In 6 patients it was elevated (in one of them eosinophilia was present before mesalazine commencement). BAL fluid examination, available in 10 patients, showed diversity of patterns. In different cases the domination of neutrophils [23], lymphocytes [20] or eosinophils [22] could be seen, but most frequently a mixed pattern was present. Not all patients with blood eosinophilia had high eosinophil counts in BAL fluid [22, 30, 31], and some patients with increased eosinophils in BAL fluid had normal eosinophil counts in the blood [17-20]. The results of histological examination of lung biopsy were available for 15 of 27 reviewed patients. Again, a diversity of patterns was present: eosinophilic pneumonia in two patients [15, 22], organising stage of eosinophilic pneumonia with eosinophilic infiltrates in one patient [19], features of organising pneumonia in five patients [12, 23, 24, 33], non-necrotising granulomas and scattered giant cells or giant cells alone in three patients $[20,23,29]$ and interstitial fibrosis in two patients [18, 23]. Only one of our patients had histopathological verification. It was Patient 1, in whom microscopic examination of resected pulmonary nodule revealed organising pneumonia with eosinophilic infiltrates. Camus et al. [34] noted that organising pneumonia in IBD patients differed from cryptogenic organising pneumonia by the richer eosinophilic infiltrates, independent of taking or not taking medication suspected to cause lung injury.

Due to their presentation, typically with new-onset dyspnoea, fever, cough, changes in chest X-ray and elevated indices of inflammation, a chest infection was first suspected in our patients as well as in the other patients from the literature. As a consequence, an empirical antibiotic therapy and an effort to identify a causative microbiological factor was the first-line management. Very rarely in those patients cultures yielded a positive result, but even in those cases use of proper antibiotics failed to bring any improvement. Pulmonary tuberculosis is one of the major considerations in these patients, especially in patients with more insidious onset of pulmonary and general symptoms and a history of immunosuppressants use. Patient 3, with a history of a pulmonary tuberculosis in a family member, GCs use in the past and chronic breathlessness, sweats and weight loss as presenting symptoms, was a good example of such a situation. Diagnostic tests for tuberculosis in that patient gave confusing results with negative direct microscopic examination of BAL fluid and negative blood T-SPOT TB test, on one hand, and a positive genetic probe and inconclusive culture of BAL fluid, on the other hand. This patient was given treatment with GCs for UC flare, which resulted in a significant improvement of respiratory symptoms and radiological picture, which in our opinion was clear evidence against tuberculosis.

In Patient 1, the radiological picture of multiple masses in the lungs and very high ESR aroused concerns about a haematological mali- 
gnancy as a cause. In Patient 2, chest pain and triangular-shaped subpleural opacities in the chest X-ray as well as an antibiotic failure directed differential thinking towards a pulmonary embolism with pulmonary infarctions. IBD is a well-recognised risk factor for thromboembolic disease [35-38]. Use of additional diagnostic tools such as histopathological examination of lung biopsy in one case and pulmonary CT angiography in the other case, made it relatively easy to exclude these conditions. It was more difficult to decide whether the pulmonary pathologies in our patients developed independently of the intestine disease and mesalazine action, or in connection with either of them. No conclusive proof exists either for a connection between lung pathology and IBD, or for a connection between lung pathology and mesalazine. Mesalazine together with its predecessor, sulphasalazine, are the main representatives of anti-inflammatory agents based on 5-aminisalicylic acid (5-ASA). In the German registry [39] 70\% of patients with UC were treated with those medications. Sulphasalazine is well known for its clinically important side effects, which affect up to $20 \%$ of users and include gastroenterological manifestations, hepatic dysfunction, skin rashes, arthralgia and fever. The most serious toxicity, however, is associated with blood dyscrasias and, less frequently, with pulmonary pathology. Parry et al. [40] summarised 50 patients reported in the literature in the years 1972-1999 as possible cases of sulphasalazine-induced lung toxicity. Sulphasalazine consists of 5-ASA in conjugation with sulphapyridine, and the letter component was thought to be responsible for the majority of side-effect reactions. Mesalazine, which does not contain the sulphur moiety, was introduced with hope to reduce systemic side effects and allergic reactions. Unfortunately, mesalazine appeared to cause adverse effects in around 3\% of users, mostly headaches, diarrhoea, nausea and worsening of the colitis [41]. The incidence of mesalazine-induced lung disease is unknown. As mentioned above, hypotheses on a connection between mesalazine and pulmonary disease are based on clinical observations, and those are confusing. Evidence in favour of the hypothetical toxic effect of mesalazine found in the reviewed papers included: 1) continuation of mesalazine administration, even in a reduced dose or even if GCs were added, caused worsening of clinical condition, hypoxaemia, opacities on chest X-ray and pulmonary function tests in some patients [14, 20, 22, 25, 30, 32]; 2) lymphocytes stimulation test or basophile degranulation test for mesalazine yielded positive results in some patients [13, 19, 28]; 3) clinical and radiologic symptoms resolution was observed, usually within days or weeks from mesalazine discontinuation [13-15, 17-19, 27]; 4) reintroduction of mesalazine caused recurrence of symptoms within 2 days to 2 weeks in some patients [20, 21, 27]; and 5) in some patients with a history of previous toxicity of sulphasalazine, mesalazine caused the same effects [16]. In contrast, however, the following arguments question the contribution of mesalazine to the development of lung pathology: 1) successful reinstitution of mesalazine after an episode of its supposed lung toxicity in some patients [17, 33]; 2) complete resolution of pulmonary problems without mesalazine cessation or any other action in some patients [29, 34], even in patients with positive mesalazine lymphocyte stimulation tests [28]; and 3) occurrence of clinically, radiologically and histopathologically identical pulmonary disease in IBD patients not exposed to 5-aminosalicylic acid derivatives [24, 29, 34, 42-48]. Blood eosinophilia is considered to be a factor suggestive of drug-induced reaction. However, there are cases showing that not only blood eosinophilia but also BAL eosinophilia and even eosinophilic pneumonitis may occur in IBD without connection to medications [34]. The role of eosinophils in IBD has been noted but not fully understood [49].

As our review of the literature showed, pulmonary disease in IBD patients responded well to GCs, but spontaneous regression was seen in numerous patients as well. Most commonly mesalazine cessation and treatment with GCs were applied resulting in a rapid improvement [12, 23, 26, 31-33]. This approach was applied in Patient 2, in whom mesalazine was stopped and GC was commenced. Mesalazine suppositories were withdrawn as well, as there are some reports suggesting a relationship between this type of mesalazine preparation and lung toxicity $[50,51]$. Patient 1 decided to continue with mesalazine and declined treatment with GCs. Patient 3 was treated with GCs and subsequently with other immunomodulatory drugs in addition to mesalazine, due to IBD activity. In all of them the outcome in terms of respiratory system disease was good. 


\section{Conclusions}

Pulmonary pathology in the course of IBD remains an interesting subject for further investigation.

\section{Conflict of interest}

The authors declare no conflict of interest.

\section{References:}

1. Dignass A., Eliakim R., Magro F. et al. Second European evidence-based consensus on the diagnosis and management of ulcerative colitis Part 1: Definitions and diagnosis. J. Crohns Colitis 2012; 6: 965-990.

2. Van Assche G., Dignass A., Panes J. et al. The second European evidence-based consensus on the diagnosis and management of Crohn's disease: Definitions and diagnosis. J. Crohns Colitis 2010; 4: 7-27.

3. Berstein C.N., Blanchard J.F., Rawsthorne P. et al. The prevalence of extraintestinal diseases in inflammatory bowel disease: a population-based study. Am. J. Gastroenterol. 2001; 96: 1116-1122.

4. Lakatos L., Pandur T., David G. et al. Association of extraintestinal manifestations of inflammatory bowel disease in a province of western Hungary with disease phenotype: results of a 25-year follow-up study. World J. Gastroenterol. 2003; 9: 2300-2307.

5. Ricart E., Panaccione R., Loftus Jr E.V. et al. Autoimmune disorders and extraintestinal manifestations in first-degree familial and sporadic inflammatory bowel disease: a case control study. Inflamm. Bowel Dis. 2004; 10: 207-214.

6. Berstein C.N., Wajda A., Blanchard J.F. The clustering of other chronic inflammatory diseases in inflammatory bowel disease: a population-based study. Gastroenterology 2005; 129: 827-836.

7. Storch I., Sachar D., Katz S. Pulmonary manifestations of inflammatory bowel disease. inflamm. Bowel Dis. 2003; 9: 104-115.

8. Saxon A., Shanahan F., Landers C. et al. A distinct subset of antineutrophil cytoplasmic antibodies in association with inflammatory bowel disease. J. Allergy Clin. Immunol. 1990; 86: $202-210$.

9. Cambridge G., Rampton D.S., Stevens T.R. et al. Anti-nuclear antibodies in inflammatory bowel disease: prevalence and diagnostic role. Gut 1992; 33: 668-674.

10. Folwarczny C., Noehl N., Endres S.P. et al. Antinuclear autoantibodies in patients with inflammatory bowel disease. Dig. Dis. Sci. 1999; 42: 1593-1597.

11. Targan S.R. The utility of ANCA and ASCA in inflammatory bowel disease. Inflamm. Bowel Dis. 1999; 5: 61-63.

12. Swinburn C.R., Jackson G.J., Cobden I. et al. Bronchiolitis obliterans organising pneumonia in a patient with ulcerative colitis. Thorax 1988; 43: 735-736.

13. Le Gros V., Saveuse H., Lesur G. Lung and skin hypersensitivity to 5-aminosalicylic acid. BMJ 1991; 302: 970.

14. Reinoso M.A., Schroeder K.W., Pisani R.J. Lung disease associated with orally administered mesalamine for ulcerative colitis. Chest 1992; 101: 1469-1471.

15. Honeybourne D. Mesalazine toxicity. BMJ 1994; 308: 533-534.

16. Lim A.G., Hine K.R. Fever, vasculitic rash, arthritis, pericarditis, and pericardial effusion after mesalazine. BMJ 1994; 308: 113.

17. Muzzi A., Ciani F., Bianchini D. et al. Adverse pulmonary effects of mesalamine. Chest 1995; 108: 1181.

18. Lazaro M.T., Garcia-Tejero M.T., Diaz-Lobato S. Mesalamine-induced lung disease. Arch. Intern. Med. 1997; 157: 462.

19. Tanigawa K., Sugiyama K., Matsuyama H. et al. Mesalazine-induced eosinophilic pneumonia. Respiration 1999; 66: 69-72.

20. Sviri S., Gafanovich I., Kramer M. et al. Mesalamine-induced hypersensitivity pneumonitis: a case report and review of the literature. J. Clin. Gastroenterol. 1997; 24: 34-36.
21. Guslandi M. Respiratory distress during mesalamine therapy. Dig. Dis. Sci. 1999; 44: 48-49.

22. Saltzman K., Rossoff L.J., Gouda H., Tongia S. Mesalamine-induced unilateral eosinophilic pneumonia. AJR 2001; 177: 257-257.

23. Foster R.A., Zander D.S., Mergo P.J., Valentine J.F. Mesalamine-related lung disease: clinical, radiographic, and pathologic manifestations. Inflamm Bowel Dis 2003; 9: 308-315.

24. Casey M.B., Tazelaar H.D., Myers J.L. et al. Noninfectious lung pathology in patients with Crohn's disease. Am. J. Surg. Pathol. 2003; 27: 213-219.

25. Actis G.C., Ottobrelli A., Baldi S. et al. Mesalamine-induced lung injury in a patient with ulcerative colitis and a confunding autoimmune background: a case report. Mt Sinai J. Med. 2005; 72: 136-140.

26. Harris A., Eswaran S., Bosworth B. et al. Mesalamine-induced pneumonitis and serum sickness-like reaction. Gastroenterol. Hepatol. 2007; 3: 875-877.

27. Actis G.C., Marzano A., Pellicano R., Rizzetto M. How important is mesalamine in the maintenance of steroid-refractory colitis? 2008; 14: 1026.

28. Kasuga A., Mandai Y., Katsuno T. et al. Pulmonary complications resembling wegener's granulomatosis in ulcerative colitis with elevated proteinase-3 anti-neutrophil cytoplasmic antibody. Intern. Med. 2008; 47: 1211-1214.

29. Nguyen T., Shepela C., Patnaik M., Jessurun J. Pulmonary nodules as an extra-intestinal manifestation of inflammatory bowel disease: a case series and review of the literature. Dig. Dis. Sci. 2009; 54: 1135-1140.

30. Sposato B., Allergi M.P., Chigiotti S. et al. Mesalazine-induced multi-organ hypersensitivity. Clin. Drug Investig. 2010; 30: 413-417.

31. Kevans D., Green J., Galvin L. et al. Mesalazine-induced bronchiolitis obliterans organizing pneumonia (BOOP) in a patient with ulcerative colitis and primary sclerosing cholangitis. Inflamm. Bowel Dis. 2011; 17: E137-8.

32. Fouka E., Stefanopoulou P., Dramba V. et al. Acute interstinal lung disease in a patient with ulcerative colitis: Case report and literature review. Pneumon. 2012; 25: 320-324.

33. Aydoğdu M., Cürsel G., Özyilmaz E. et al. A case of ulcerative colitis complicated with bronchiolitis obliterans organizing pneumonia (BOOP) and air leak syndrome. Turk J. Gastroenterol. 2012; 23: 590-595.

34. Camus P., Piard F., Ashcroft T. et al. The lung in inflammatory bowel disease. Medicine (Baltimore) 1993; 72: 151-183.

35. Grainger M.J., West J., Card T.R. Venous thromboembolism during active disease and remission in inflammatory bowel disease: a cohort study. Lancet 2010; 375: 657-663.

36. Novacek G., Weltermann A., Sobala A. et al. Inflammatory bowel disease is a risk factor for recurrent venous thromboembolism. Gastroenterology 2010; 139: 779-787.

37. Murthy S.K., Nguyen G.C. Venous thromboembolism in inflammatory bowel disease: an epidemiological review. Am. J. Gastroenterol. 2011; 106: 713-718.

38. Yuhara H., Steinmaus C., Corley D. et al. Meta-analysis: the risk of venous thromboembolism in patients with inflammatory bowel disease. Aliment. Pharmacol. Ther. 2013; 37: 953-962.

39. Bokemeyer B., Hardt J., Hüppe D. et al. Clinical status, psychosocial impairments, medical treatment and health care costs for patients with inflammatory bowel disease (IBD) in Germany: An online IBD registry. Journal of Crohn's and Colitis 2013; 7: 355-368.

40. Parry S.C, Barbatzas C., Peel E.T, Barton J.R. Sulphasalazine and lung toxicity. Eur Respir J 2002; 19: 756-764.

41. Brimblecombe R. Mesalamine: a global safety evaluation. Scand. J. Gastroenterol. Suppl. 1990; 172: 66

42. Forrest J.A.H., Sherman D.J.C. Pulmonary vasculits and ulcerative colitis. Am. J. Dig. Dis. 1975; 20: 482-486.

43. Kedziora J.A., Wolff M., Chang J. Limited form of wegener's granulomatosis in ulcerative colitis. Am. J. Roentgenol. Radium Ther. Nucl. Med. 1975; 125: 127-133.

44. Balestra D.J., Balestra S.T., Wasson J.H. Ulcerative colitis and steroid-responsive, diffuse interstitial lung disease. A Trial of $\mathrm{N}=1$. JAMA 1988; 260: 62-64. 
45. Baron F.A. Hermanne J.-P. Dowlati A. et al. Bronchiolitis obliterans organizing pneumonia and ulcerative colitis after allogenic bone marrow transplantation. Bone Marrow Transplant 1998; 21: 951-954.

46. Stebbing J., Askin F., Fisheman E., Stone J. Pulmonary manifestations of ulcerative colitis mimicking Wegener's granulomatosis. J. Rheumatol. 1999; 26: 1617-1621.

47. Marten K., Fend F., Hautmann H. et al. Fatal acute exacerbation of usual interstinal pneumonia in ulcerative colitis. Br. J. Radiol. 2005; 78: 762-766
48. Jang E.C., Choi J.H., Ryu J.-S. et al. Organizing pneumonia presenting after ulcerative colitis remission. J. Thorac. Dis. 2013; 5: E71-E73.

49. Woodruff S.A., Masterson J.C., Fillon S. et al. Role of eosinophils in inflammatory bowel and gastrointestinal diseases. J. Pediatr. Gastroenterol. Nutr. 2011; 52: 650-661.

50. Welte T., Hamm H., Fabel H. Mesalazine alveolatis. Lancet 1991; 338: 1273.

51. Kim J.H., Lee J.-H., Koh E.-S. et al. Acute eosinophilic pneumonia related to a mesalazine suppository. Asia Pac. Allergy 2013; 3: 136-139. 